\title{
Reactive Power Compensation in Railways Using Active Impedance Concepts
}

\author{
${ }^{1}$ Rosanna Thomas, ${ }^{2}$ Dr. Narayanappa, ${ }^{3}$ Dr. Thanushkodi \\ ${ }^{I}$ M.E Scholar in Power Systems Engineering, Department of Electrical and Electronics, Adhiyamaan College of \\ Engineering, Hosur,TN,India \\ ${ }^{2}$ M.E., PhD Professor, Department of Electrical and Electronics, Adhiyamaan College of Engineering, \\ Hosur,TN,India \\ ${ }^{3}$ Director, Akshaya College of Engineering and Technology Coimbatore, India
}

\begin{abstract}
Traction systems are huge consumers of reactive power. It due to the presence of inductive reactance in traction transformer, traction motors, auxiliary motors, smoothening reactor. Reactive power keeps on varying in a traction substation as the number of locomotives increases and decreases in its working environment. As a result of this a detailed study of reactive power is required in traction substation and the traditional fixed capacitors should be replaced with active filter based on PI controller.
\end{abstract}

Keywords- traction substation, Indian railway, reactive power, active power, voltage imbalance, PI controller, shunt active filter.

\section{Introduction}

A traction system is the most widely used transportation system across the world for long and short distance. India ranked fourth covering a total length of 64,015 kilometers. The most part of it is electrified. Annually, approximately 30 billion units of electricity is consumed by Railways, out of which 10.4 billion units are used for electric traction purpose. Railway is paying approximate Rs. 5000 crores every year on account of traction energy charges which constitutes about $20 \%$ of total revenue budget of railways.

An electrical traction system is pulled with an engine system which consist of highly reactance elements such as DC series motors transformer, auxiliary motors for compressors, baby compressors and cooling fans. Due to this reactive element in the engine traction system a large reactive power is consumed by the traction system. Also, nowadays single phase rectifiers are widely used in the electrical traction loads in many countries, which caused the issues of harmonics and reactive power.

The harmonics and reactive power have negative influences on the power supply system. To compensate reactive power, fixed capacitors have been widely used. One of the main disadvantages of fixed capacitor is that its compensation amount is also fixed and cannot be changed with the variation of load. Another one is that 'resonance may occur between the fixed capacitor and the impedance of power supply system. Recently TSF ( Thyristor Switched Filter) has been used in traction system.

There are several group of passive filter in TSF, with the variation of reactive power, an appropriate number of groups of TSF are switched on. Thus the compensation amount of TSF can be adjusted with the variation of load. However, resonance will still possible to occur between TSF and the impedance of power supply system.

This paper is concentrated on Palgat railway division traction substation,kerala State, India. The Indian Railways employ single phase $25 \mathrm{kV}$ Traction Substation (TSS) for supplying power at Electric Traction loads. Few key features of Traction loads are single phase 25-KV system, high load dynamics, usually inject lower order harmonics and wide supply voltage variation. Conventional fixed shunt capacitor banks alone cannot maintain a good power factor at the incoming supply lines due to load dynamics. To achieve good power factor nearing unity to avoid penalty (for lagging or leading poor power factor), to gain the better power factor benefits in the electricity bills, to reduce the Maximum Demand and applicable charges in the electricity bills, and to improve power quality, the substations need to employ dynamic reactive power compensation equipment. The equipment needs to be connected on the $25 \mathrm{kV}$ network and dynamic compensation of traction load reactive power is to be achieved using either Thyristor Controlled Reactor (TCR) or Thyristor Switched Capacitor (TSC) or IGBT based realtime advanced dynamic reactive power compensator.

In this paper use an IGBT based Shunt Active Power Filter (SAPF) is used, which utilize the features of modern power electronic technology. Different types of APFs are used in electric traction system. The reactive power, the harmonics, voltage imbalance and negative sequence current can be compensated effectively. However, when the complexity of control is increased the use of power electronics components in the topologies also increased. In addition, these APF use instantaneous power theory to determine the compensating currents, which is not suitable for single phase traction power systems. 
Here proposed a new active power filter based on PI controller. Since the voltage source converter is important part in APF, more care is given to design of DC side capacitor. The controlling of DC capacitor voltage along with reactive power compensation and voltage balancing control is adopted here to improve the system behavior. The performance analysis will be done with comparative study of power factor and reactive power compensation. All the simulation work has been done on MATLAB.

\section{Proposed System}

Indian railways uses single phase $25 \mathrm{kV}, 50 \mathrm{~Hz}$ supply system, by stepping down the $110 \mathrm{kV}$ grid supply voltage. An equivalent supply system and step-down transformer of equivalent rating is designed and developed using MATLAB/SIMULINK. According to the readings obtained from the traction substation, Palagat railway division we designed an equivalent traction load with fixed capacitance compensation. But this capacitor compensation won't be sufficient for compensating power quality problems like imbalance and sag in voltage, insufficient active and reactive power, harmonics and overcompensation in case of light loads in traction substation. As a result of this power quality problems in supply side also will get disturbed and the railways will have to pay extra penalties to the supply system authorities.

We designed a shunt active filter for which is the best and simplest solution for compensating these power quality problems in Indian environment. This system is also economically feasible with a simple PI controller. The shunt active filters are based on IGBT a solid state device. Fig.1 shows the schematic diagram of the proposed system based on the shunt active filter.

Fig.1 gives an idea of the proposed system which is a shunt active filter based on PI controller action which is simple and economically feasible for Indian environment. It consists of $25 \mathrm{kV}, 50 \mathrm{~Hz}$ supply voltage, shunt active filter and traction load. PI control action is done by generating a reference current by comparing the input voltage and the load voltage and then the reference current is given to the PWM pulse generator which is given to the gate supply of the IGBT. A DC voltage is given as a backup supply for the compensation. Fig .1 shows the block diagram representation of the proposed system.

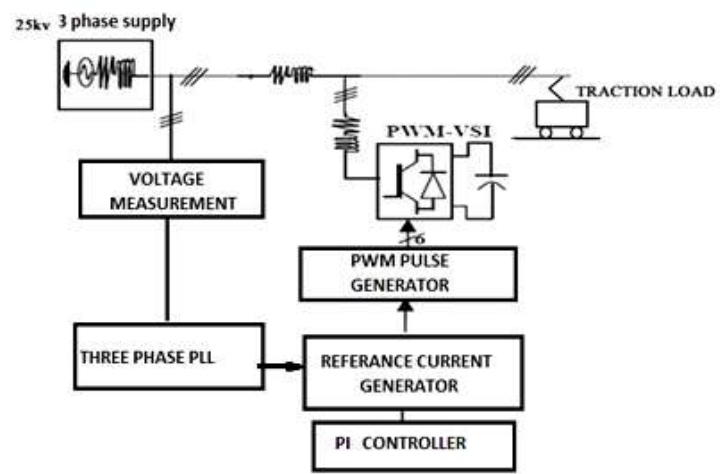

Fig.1 Schematic diagram of the proposed system with shunt active compensation.

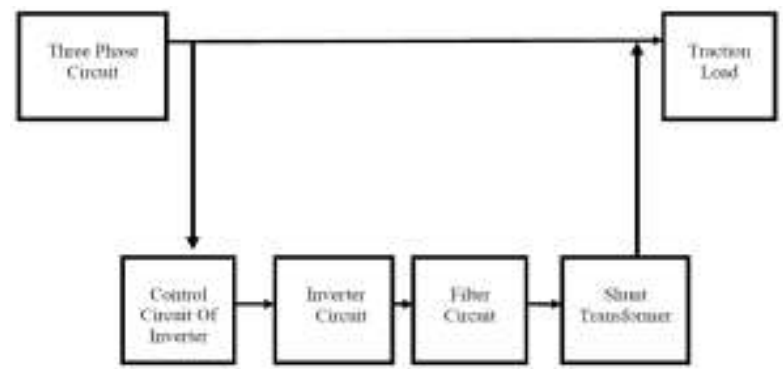

Fig.2 Block diagram representation of the proposed system

The block diagram of the proposed system is shown in the figure below. From the diagram can see that a three phase supply is supplying the traction load and the measurement of this voltage is given to the control circuit of the shunt active power filter. Were this measured value is compared with a reference value and given to a PI controller whose output is given to PWM pulse generator and is given to the gate circuit of the inverter circuit . the inverter output is given to a LC filter to reduce the distortions . this inverter output is given to the three phase circuit through a shunt transformer .

A three phase supply is given to the traction distribution system with maintaining equal load management done effectively. An equivalent traction load is also designed with the values of active and reactive 
power obtained from the traction substation. As the traction system is a highly inductive load there should be an effective dynamic reactive power compensation system. In accordance to the values obtained from the traction substation a traction load is modeled with equivalent RLC load with fixed capacitance compensation.

\section{Simulation Of Proposed System}

The circuit of a traction power system with equivalent traction loads on three phases supply and traction load with reactive power compensation is implemented using MATLAB/ SIMULINK.

A simulation model of traction power supply system with load is created in MATLAB/SIMULINK so as investigate circuit waveforms, dynamic and steady -state performance, voltage and current ratings and real and reactive power ratings. The case study of voltage imbalance, sag, low power factor at the load side is simulated and results are presented below.

TABLE I

SIMULATION PARAMETERS FOR TRACTION LOAD

\begin{tabular}{|l|c|}
\hline Active Power & $2.87 \mathrm{MW}$ \\
\hline Reactive Power Inductive & $1.44 \mathrm{MVAR}$ \\
\hline Reactive Power Capacitive & $7 \mathrm{kVAR}$ \\
\hline
\end{tabular}

TABLE II

SIMULATION PARAMETERS FOR LINE LOSSES IN THREE PHASE POWER SUPPLY

\begin{tabular}{|l|l|l|l|}
\hline $\mathrm{R}-$ phase & $\mathrm{R}=1000$ & $\mathrm{~L}=.0138 \mathrm{e}-2$ & $\mathrm{C}=.24 \mathrm{e}-3$ \\
\hline Y- phase & $\mathrm{R}=2000$ & $\mathrm{~L}=.0276 \mathrm{e}-2$ & $\mathrm{C}=.24 \mathrm{e}-3$ \\
\hline $\mathrm{B}$ - phase & $\mathrm{R}=3000$ & $\mathrm{~L}=.0404 \mathrm{e}-2$ & $\mathrm{C}=.24 \mathrm{e}-3$ \\
\hline \multicolumn{5}{|r}{ TABLE III }
\end{tabular}

SIMULATION PARAMETERS FOR THE PROPOSED SYSTEM

\begin{tabular}{|l|l|}
\hline Phase to phase rms voltage & $77.78 \mathrm{MV}$ \\
Frequency & $50 \mathrm{~Hz}$ \\
Nominal Power & $13.5 \mathrm{M} \mathrm{W}$ \\
Frequency & $50 \mathrm{~Hz}$ \\
Primary Voltage & $110 \mathrm{kV}$ \\
Secondary Voltage & $25 \mathrm{Kv}$ \\
Coupling Inductance, & $\mathrm{L}=1 \mathrm{mH}$ \\
Coupling Resistance & $\mathrm{R}=200 \Omega$ \\
\hline
\end{tabular}

\section{Results And Discussions}

A simulation model of traction power supply system with load is created in MATLAB/SIMULINK so as investigate circuit waveforms, dynamic and steady -state performance, voltage and current ratings and real and reactive power ratings. The case study of voltage imbalance, sag, low power factor at the load side is simulated and results are presented below.

\section{A. Input Voltage}

The diagram Fig. 3 the waveform of the input voltage $25 \mathrm{kV}$. The voltage is obtained by stepping down the SEB supply voltage $110 \mathrm{kV}$ to $25 \mathrm{kV}$ in MATLAB simulation.

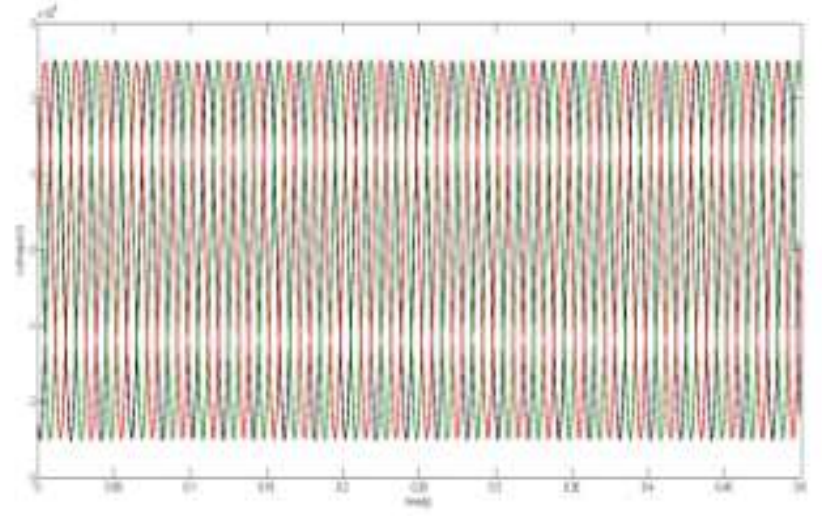

Fig. 3 Input voltages of the input bus 


\section{B. Load Voltage with Traction Load}

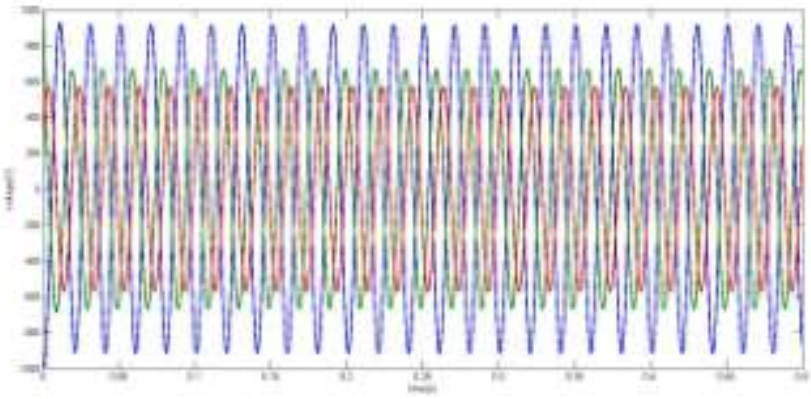

Fig. 4 load voltage without compensation

The above Fig. 4 shows the voltage waveform of the traction power supply with the load connected in each phase. From the diagram can see a voltage sag, unbalance in voltages and change in power factor from the input waveform. These problems are typical power quality problems and the traction distributions will have to suffer lot losses both in terms of efficiency and economy. Due to a reduce power factor in the power system they have to give penalties to the respective substation.

Active power consumption of traction load

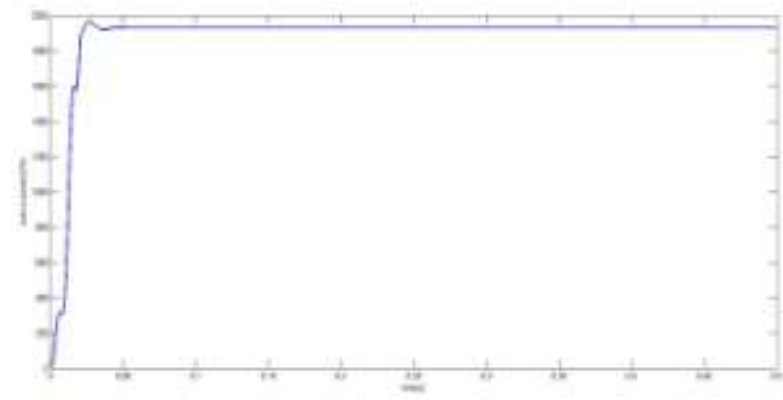

Fig. 5 Single phase active power without compensation

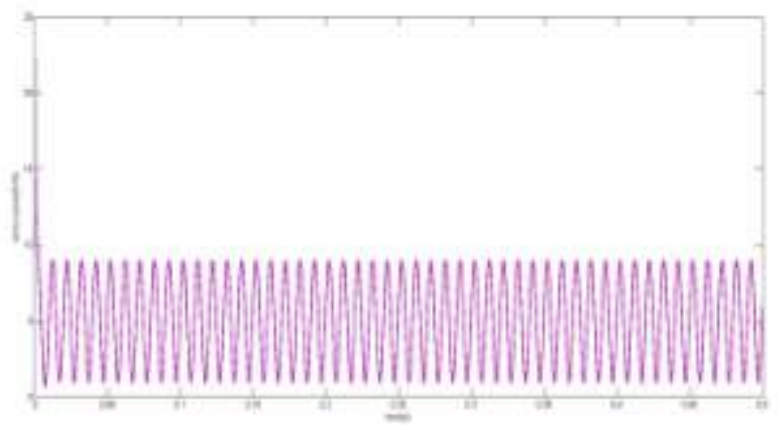

Fig. 6 Three phase active power without compensation

The Fig. 5 and Fig 6 shows the active power demand of the traction substation with traction load on traction substation without load compensation.

\section{Reactive power consumption by traction system}

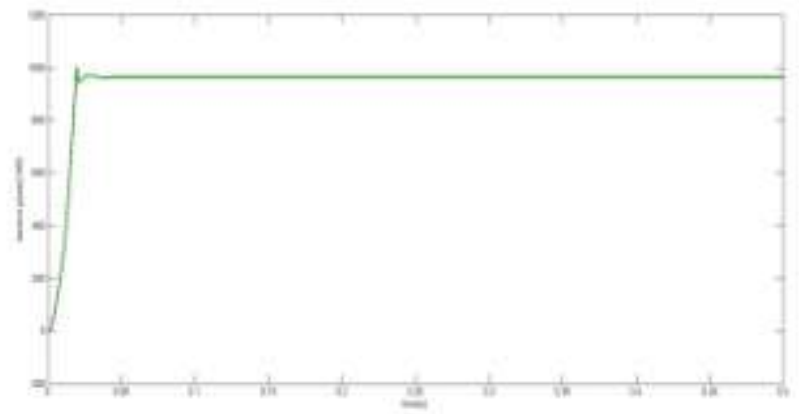

Fig. 7 Single phase reactive power without 
With dynamic load variation in traction substation reactive power gets variation. This is shown in the above diagram compensation

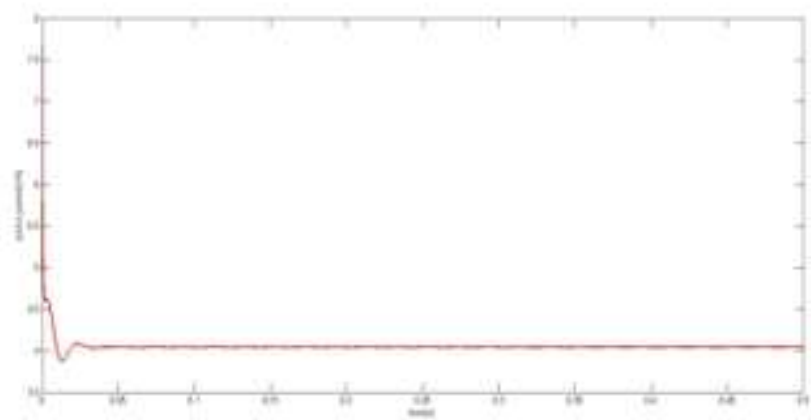

Fig. 8 Three phase reactive power without compensation

The single phase and three phase reactive power is shown in the above waveform shown in Fig. 5.6 and Fig. 5.7, from this can conclude that a high reactive power compensating device is needed to supply reactive power to the dynamic traction load which will also boost active power and voltage in the system.

\section{Load Voltage after Compensation}

The voltage across the load with shunt active filter compensation is shown in the figure 5.8 . can see an increase in the voltage after compensation to $4000 \mathrm{~V}$

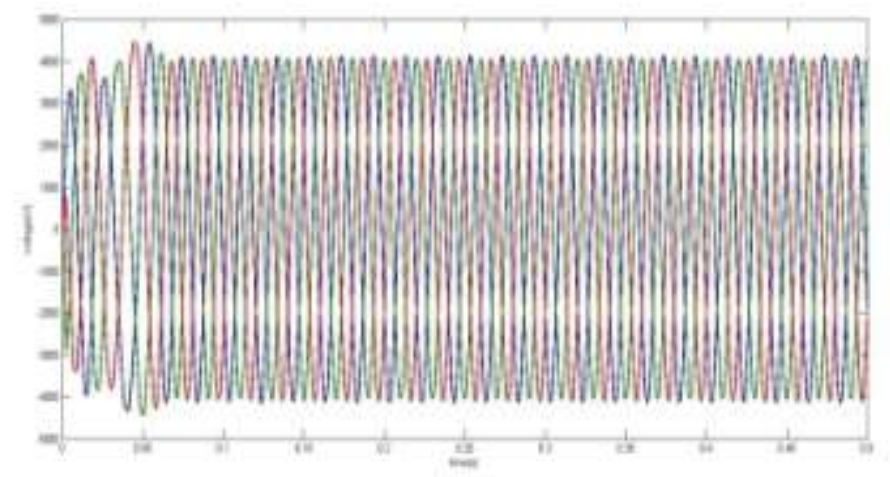

Fig..9 Voltage waveform at the load terminals after compensation

\section{E. Active Power after compensation}

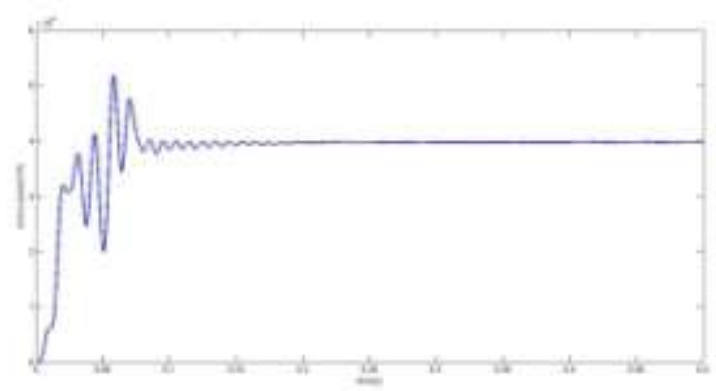

Fig. 10 Single phase active power after compensating

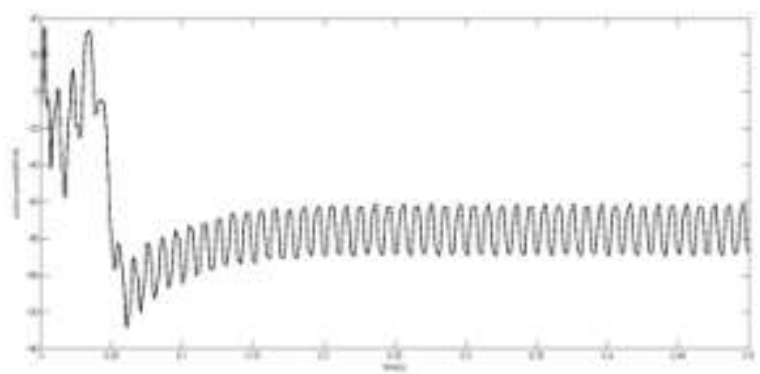

Fig. 11 Three phase active power after compensating 
The above figures fig 10,11 shows the single phase and three phase active and reactive power after connecting the reactive power compensating device system, the shunt active filter in the system. see an increase in the active power from the figure.

\section{F. Reactive Power after Compensation}

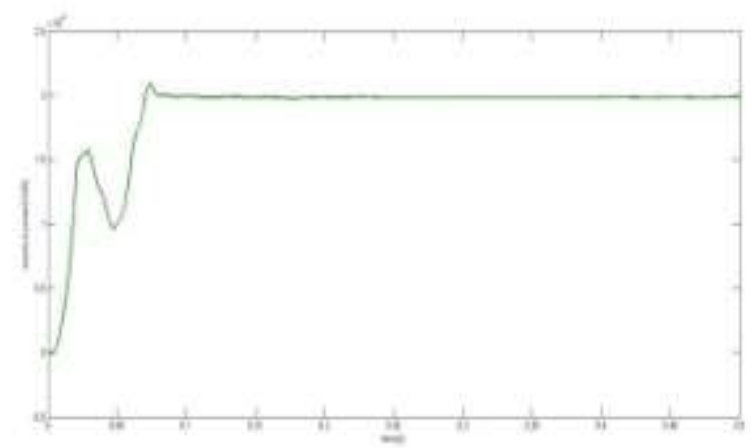

Fig.12 Single phase reactive power after compensating

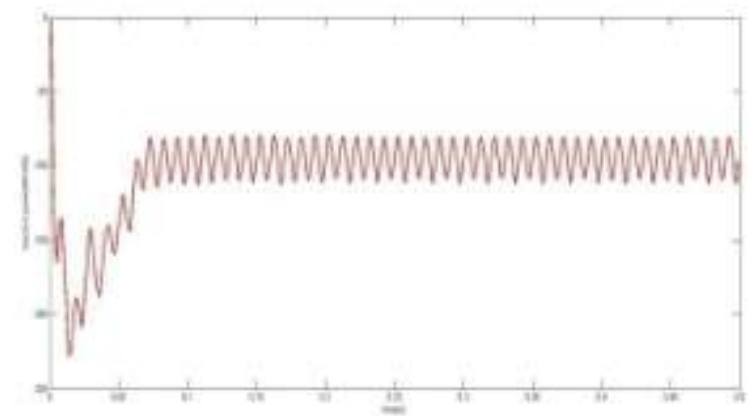

Fig. 13 Three phase reactive power after compensating

The above Fig. 12 and Fig. 13 shows the waveform of reactive power after applying the compensation to it. can see that as the active power is boosted to the system, the reactive power reduces and stabilizes the system.

\section{G. Output Voltage with Single Phase Distribution of Traction}

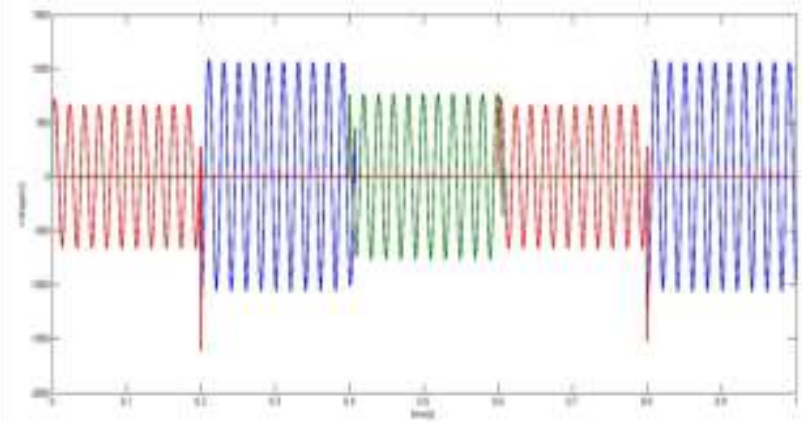

Fig.14 Output voltage with Single Phase Distribution of Traction

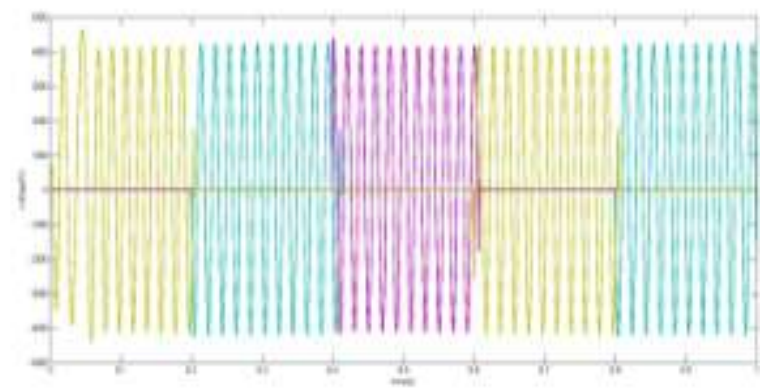

Fig. 15 Output voltage after compensation 


\section{H. Total Harmonic Distortion (THD)}

The THD of a signal is a measurement of the harmonic distortion present and defined as the ratio of the sum of the powers of all the harmonic components to the power of fundamental frequency. THD is used to power quality of electric power systems, in power systems, lower THD means reduction in peak currents, heating, emissions and core loss in motors. In this MATLAB simulation can compute THD by Fast Fourier Transforms (FFT) analysis. THD of input voltage current, load voltage with or without load can be analyzed with FFT as follows.

\section{THD in Input Voltage}

THD can be computed with FFT analysis.thw below diagram shows the THD levels in the input voltage, THD is. $01 \%$.

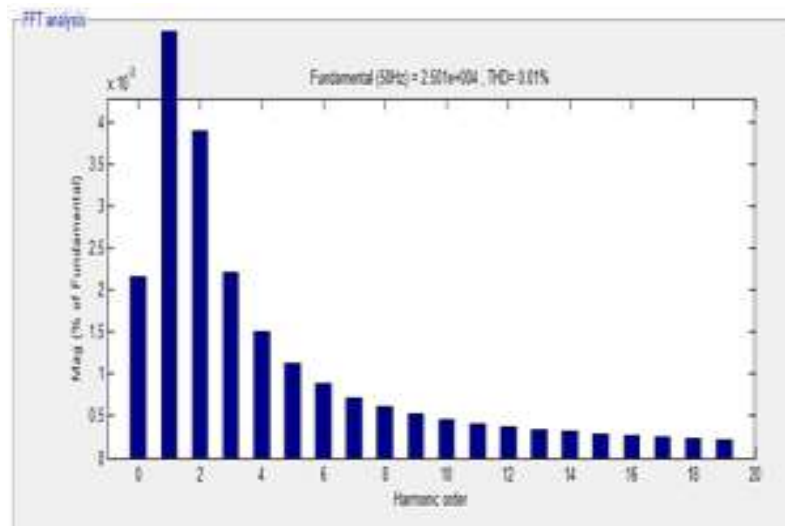

Fig. 15 THD of input voltage

\section{J. THD of Input Current}

THD can be computed with FFT analysis.thw below diagram shows the THD levels in the input current, THD is . $01 \%$.

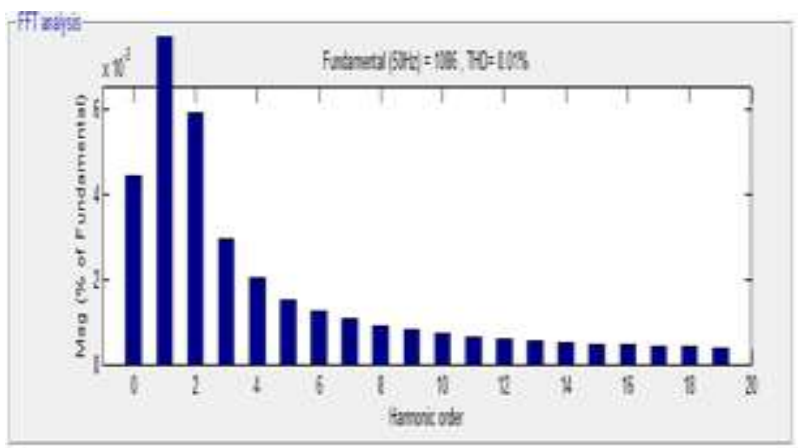

Fig. 16 THD of input current

\section{K. Load Voltage THD without Compensation}

THD can be computed with FFT analysis.thw below diagram shows the THD levels in the load voltage without Compensation circuit, THD is $10.45 \%$.

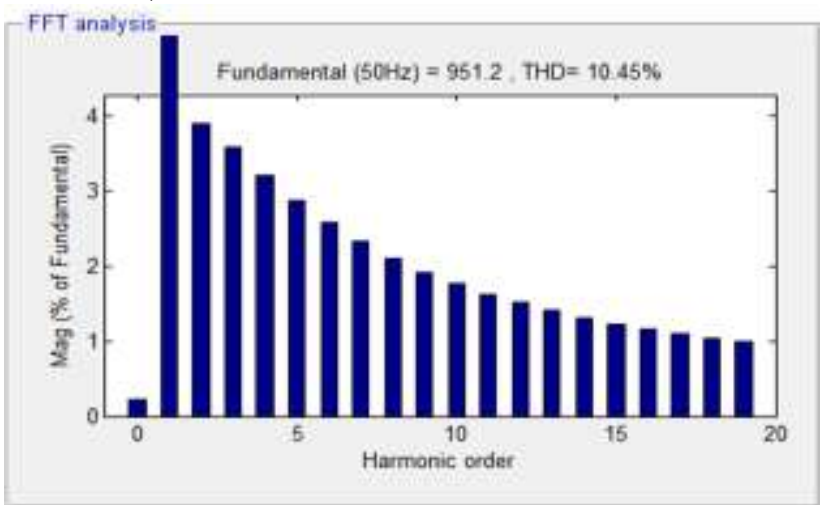

Fig.17 Load Voltage THD without Compensation 


\section{Voltage THD with Compensation}

THD can be computed with FFT analysis.thw below diagram shows the THD levels in the voltage with Compensation circuit, THD is $3.66 \%$.

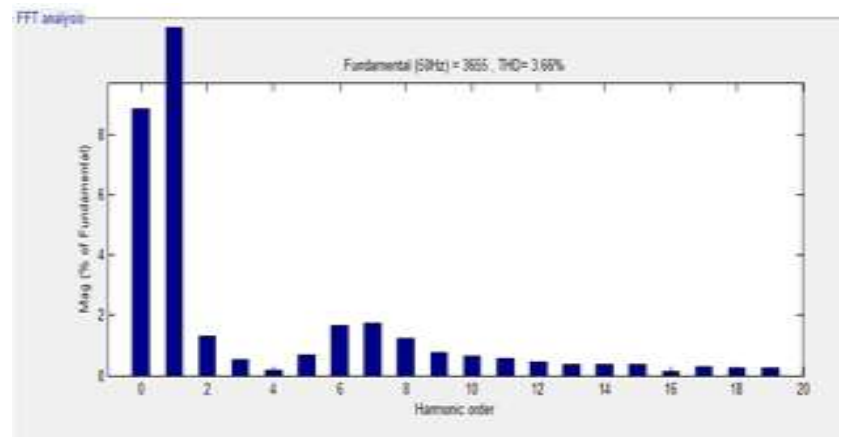

Fig. 18 Voltage THD with Compensation

\section{Conclusion}

As per the objective work is to develop reactive power compensation in the traction substation based on the values, active and reactive power of daily current, voltage obtained from the traction substation. An equivalent traction load is developed in this paper with this with an RL parallel load with the values obtained.

Reactive power requirement of traction system is studied and a similar circuit for traction power supply is simulated using MATLAB. The reactive power demand was minimised by the proposed system using active filters which is a dynamic power compensating system based on inverters with PI controller and is simulated with the help of MATLAB.

In this work a 3-phase inverter is used for the reactive power compensation. The inverter with the proposed approach can be utilized for the following

- Inject real power

- Compensates reactive power

- Compensate voltage imbalance in the system

- Reducing negative sequence current in the system

[1] Busco, B..Marino, P M. Porzio, R. Schiavo, and F. Vasca, Digital control and simulation for power electronic apparatus in dual voltage railway locomotive, IEEE Trans. Power Electron., vol. 18, no. 5, pp. 1146-1157, Sep. 2003.

[2] Han B., B. Bae, H. Kim, And S. Baek, Combined Operation Of Unified Power-quality Conditioner With Distributed Generation, IEEE transactions on power delivery, vol. 21, no. 1, January 2006.

[3] Behrooz Bahrani, Alfred Rufer, And Martin Aeberhard, catenary Voltage Support Adopting Modern Locomotives With Active Line-side Converters, IEEE Transactions On Smart Grid, Vol. 3, No. 1, March 2012 H.Cheng-Ping,W. Chi-Jui, C.Yung-Sung, P. Shih-Kai,Y. Jung-Liang, a nd H. Ming-Hong, Loading characteristics analysis of specially connected transformers using various power factor definitions, IEEE Trans. Power Del., vol. 21, no. 3, pp. 1406-1413, Jul. 2006.

[4] Celli, F. Pilo, S.B. Tennakoon, "Voltage Regulation on $25 \mathrm{kV}$ AC railway systems by using Thyristor switched capacitor", Proceedings of 9th Intl. Conference on Harmonics and Quality of Power, Vol. 2, pp. 633-638, Oct. 2000.

[5] Chen, R. J. Li, and H. Pao-Hsiang, Traction system unbalance problem-analysis methodologies, IEEE Trans. Power Del., vol. 19, no. 4, pp. 1877-1883, Oct. 2004.

[6] Hung-Yuan K. and C. Tsai-Hsiang, Rigorous evaluation of the voltage unbalance due to high-speed railway demands, IEEE Trans. Veh. Technol., vol. 47, no. 4, pp. 1385-1389, Nov. 1998.

[7] Li X. and L. Zuo," Research on balance compensation of STATCOM", in Proc. 2nd IEEE Conf. Ind. Electron., pp. 563-568,Appl., 2007

[8] Morris Brenna, And Federica Foiadelli, Analysis Of The Filters Installed In The Interconnection Points Between Different Railway Supply Systems, IEEE transactions on smart grid, vol. 3, no. 1, march 2012

[9] Otto R. A., T. H. Putman, and L. Gyugyi, Principles and applications of static, thyristor-controlled shunt compensators, IEEE Trans. Power App. Syst., vol. PAS-97, no. 5, pp. 1935-1945, Sep. 1978.

[10] Senini S. and P. J. Wolfs, Hybrid active filter for harmonically unbalanced three phase three wire railway traction loads, IEEE Trans. Power Electron., vol. 15, no. 4, pp. 702-710, Jul. 2000.

[11] Shenoy U. J., K. G. Sheshadri, K. Parthasarath ,H. P. Khincha, D. Thukaram, "Matlab/Psb Based Modeling And Simulation Of 25 Kv Ac Railway Traction System- A Particular Reference To Loading And Fault Conditions", IEEE Transactions On power electronics, vol. 21, no. 2, February 2004.

[12] Zeliang Shu, Shaofeng Xie, And Qunzhan Li, Single-phase Back-to-back Converter For Active power Balancing, Reactive Power Compensation, And Harmonic Filtering In Traction Power System, IEEE Transactions On power electronics, vol. 26, no. 2, February 2011. 